\title{
Left Posterior Middle Transition Zone of Prostate
}

National Cancer Institute

\section{Source}

National Cancer Institute. Left Posterior Middle Transition Zone of Prostate. NCI

Thesaurus. Code C128604.

The region of the prostate that is located on the anatomical left side of the posterior portion of the middle division of the transition zone. 